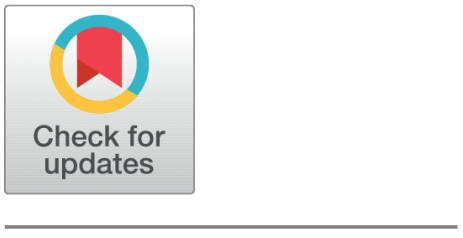

OPEN ACCESS

Received: 25-06-2020

Accepted: 25-07-2020

Published: 11-08-2020

Editor: Dr. Natarajan Gajendran

Citation: Usaid M, Soothar KK, Memon KA, Dehraj S, Hafeez U, Ain N (2020) Design of sustainable pedestrian power generator using Piezo electric sensors. Indian Journal of Science and Technology 13(29): 2956-2961. https://doi.org/ 10.17485/IJST/v13i29.1000

* Corresponding author.

ali.kamran77@gmail.com

Funding: None

Competing Interests: None

Copyright: (c) 2020 Usaid et al. This is an open access article distributed under the terms of the Creative Commons Attribution License, which permits unrestricted use, distribution, and reproduction in any medium, provided the original author and source are credited.

Published By Indian Society for Education and Environment (iSee)

ISSN

Print: 0974-6846

Electronic: 0974-5645

\section{Design of sustainable pedestrian power generator using Piezo electric sensors}

\author{
Muhammad Usaid ${ }^{1}$, Kamlesh Kumar Soothar ${ }^{2}$, Kamran Ali Memon ${ }^{2,3 *}$, \\ Sanaullah Dehraj ${ }^{4}$, Usama Hafeez ${ }^{5}$, Noor ul Ain ${ }^{6}$ \\ 1 Department of Electrical Engineering, Mehran University of Engineering \& Technology, \\ Jamshoro, Pakistan \\ 2 School of Electronic Engineering, Beijing University of Posts and Telecommunications, \\ Beijing, 100876, China \\ 3 Department of Electronic Engineering, Quaid e Awam University of Engineering, Science \\ and Technology, Nawabshah, Pakistan \\ 4 Department of Mathematics and Statistics, Quaid e Awam University of Engineering, \\ Science and Technology, Nawabshah, Pakistan \\ 5 Department of Mechanical Engineering, Mehran University of Engineering \& Technology, \\ Jamshoro, Pakistan \\ 6 School of Information and Communication Engineering, Beijing University of Posts and \\ Telecommunications, China
}

\section{Abstract}

Background/Objectives: The generation of electrical power and its utilisation is an essential practice. Currently, the energy sources are non-renewable and expensive; the demand for electric power is increasing rapidly. In this purposed work, energy is generated by pedestrian power or using locomotive pressure energy. Methods/Statistical analysis: We use a tile containing several piezoelectric transducers arranged in a series-parallel configuration so as stress or pressure applied by pedestrians can be converted in useful Electrical source. DC, AC filters and buck converters are used for smoothing purpose and to obtain required voltage level. Findings: We generated approximately 20 volts by applying the pressure of the human body on the multiple piezo tiles using anti-diodes, and the highest voltage was recorded of 45 volts without using anti-diodes. Novelty/Applications: The production and life of piezoelectric transducers has been enhanced and more wattage power is generated than existing designs. The power generated can be used directly; also, we used batteries to store power. This piezo system can be fixed in homes, schools, universities and anywhere where human movements occurr.

Keywords: Piezoelectric; piezo transducers; renewable energy; pressure

\section{Introduction}

At present, electricity has become an essential and commonly used energy resource for human lives; life without electricity is unimaginable in the current state of existence. The dependency has highlighted the rising gap between demand and supply for masses and the exploration of alternate sources of energy through different ways of power 
generation $^{(1)}$. Many electric powered gadgets have been an integral part of our high standard living style, anybody cannot go in synchronism without them, to maintain their comfort zone ${ }^{(2)}$. Several countries also face financial deficits, debts, poor recoveries from citizens. As a reason, they run out of resources to generate more power and create lag in the power sector. In populated countries, the non-conventional energy is considered as of high importance since the roads, railway stations, and bus stations there are heavily crowded, and jam-packed by the people ${ }^{(3,4)}$. The application of pressure to squeeze the piezoelectric material produces the electrical energy known as the piezoelectric effect, and the piezo transducers convert it into the electrical charges ${ }^{(5)}$. The applied mechanical force or stresses generate an electrical voltage at the output ${ }^{(6)}$. This energy is proportional to the weight of the human body or the magnitude of the pressure exerted by the body. However, this pressure should be continuously varying to produce power ${ }^{(7)}$. This purposed method gives the idea of the generation of power by walking or running on the piezoelectric materials. The amount of energy generated by piezoelectric effect can be used directly or to be stored in batteries for power backup. This proposed work is convenient, and with practically zero costs factors. ${ }^{(8)}$. The piezo transducers can be installed at public places i.e., Sidewalk pads, GYM appliances, and also for Mobile keypad and Keyboards. This can be used for many applications in rural areas where power availability is minimal, and the population/traffic of human is higher ${ }^{(9)}$. As energy management is a big challenge for an enormous population, by using this venture, we can drive both A.C as well as D.C loads through the force we apply on the piezoelectric sensors.

The existing designs in the literature present very simple designs and are unable to produce sustainable and large power which actually depends on the life of piezoelectric sensor. In ${ }^{(10)}$, the proposed design presents experimental design. In operation, piezo continuously fires a negative current spike which will damage its ability to produce power and shortening its life span by half almost, but it does not offer any protection for the long life term of piezo Sensors. Further, this model supports small scale and merely generates 0.6 Watts only. The models are almost limited to simulation design and small scale. The experimental designs on the large scale without anti parallel diodes is in fact a big challenge.

We configured a hardware-based project to produce the electrical energy by applying the weight of the human body on piezoelectric material based tiles installed. We observed the relation between weight and power generated on piezo materials. The performance of the piezoelectric effect also varies by piezo materials. We used PZT piezo material, which shows better performance than $\mathrm{PVDF}$ and $\mathrm{PbTiO}_{3}, \mathrm{PbZrO}_{3}$. The main contribution of this work is as below:

- To produce electric power using a piezoelectric material.

- To make it a more reliable or expanding life of piezo materials by overcoming the inverse piezo effect.

- To make it more reliable by using stored power (batteries).

- To observed the power generation of single piezo transducers and multi piezo transducers in series-parallel manners to get higher power.

In the rest of the paper, section II describes the hardware set up and related discussion on the components used in the proposed work. Section III describes the experiment and results, which show the effects of using single and multiple piezoelectric sensors in a series-parallel configuration to get higher output power. Finally, section IV concludes our work.

\section{Experimental setup}

In this experimental setup, we are converting the energy of applied pressure on piezoelectric materials, which is causing the phenomenon of production of electrical energy. The pressure applied on piezo tiles varies by weight; therefore, the voltage generating on piezo tiles also varies. Consider the people who are walking on piezo tiles are from $40 \mathrm{~kg}$ to $70 \mathrm{~kg}$ the relation of weight and power generated is shown in Figure 1. The graph showed that the maximum power is generated when heavy weight is applied. The maximum theoretical power generated depends upon the force applied on piezoelectric effects, therefore it can be presumed as ideal capacitor. In this project we configured multiple piezo electric materials in series and parallel ways to produce the maximum output power. Consider the piezoelectric discs are connected in series, the equivalence capacitance of $\mathrm{n}$ capacitors can be calculated as;

$$
\begin{gathered}
\frac{1}{C_{e q}}=\frac{1}{C_{1}}+\frac{1}{C_{2}}+\frac{1}{C_{3}}+\cdots+\frac{1}{C_{n}} \\
\text { The charge } Q \text { is given as, } Q=C * V ; \\
\frac{1}{C}=\frac{V}{Q}
\end{gathered}
$$


By replacing Equation (1) and Equation (2), The equivalent capacitance of capacitors is given as below:

$$
\frac{V_{e q}}{Q}=\frac{V_{1}}{Q}+\frac{V_{2}}{Q}+\frac{V_{3}}{Q}+\cdots+\frac{V_{n}}{Q}
$$

Hence the voltage generated in series is the sum of all individual voltage generated across connected piezoelectric disks.

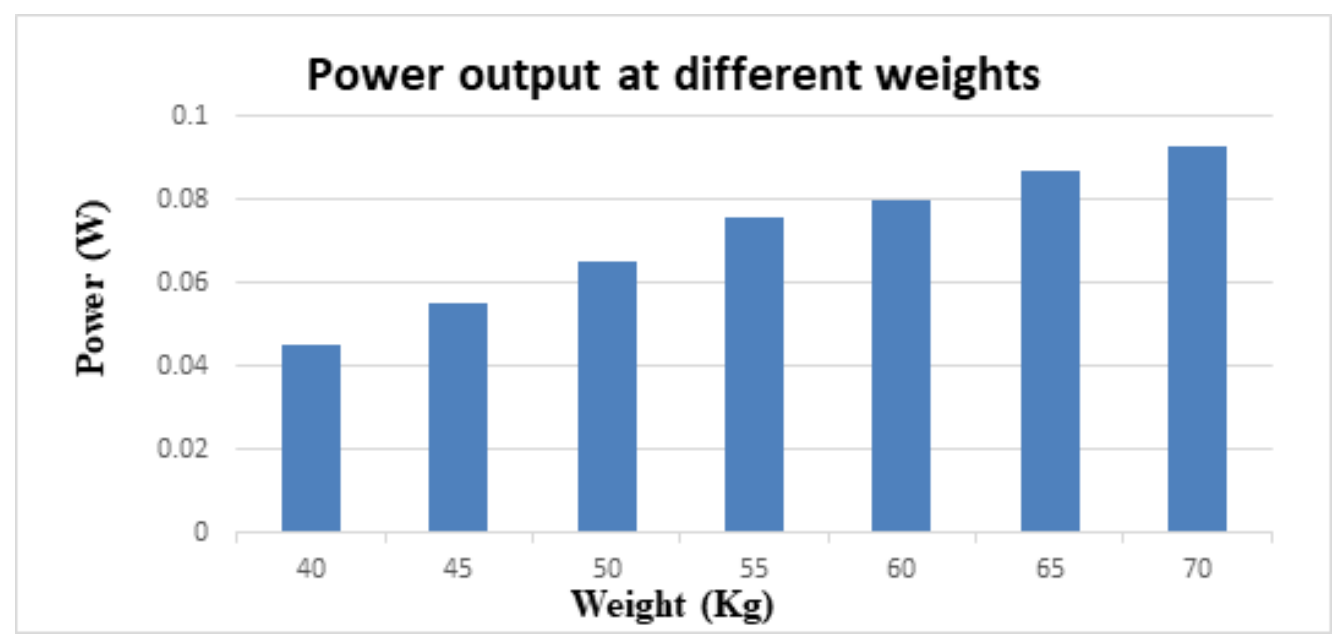

Fig 1. Weight versus power output

\subsection{Working diagram of piezoelectric}

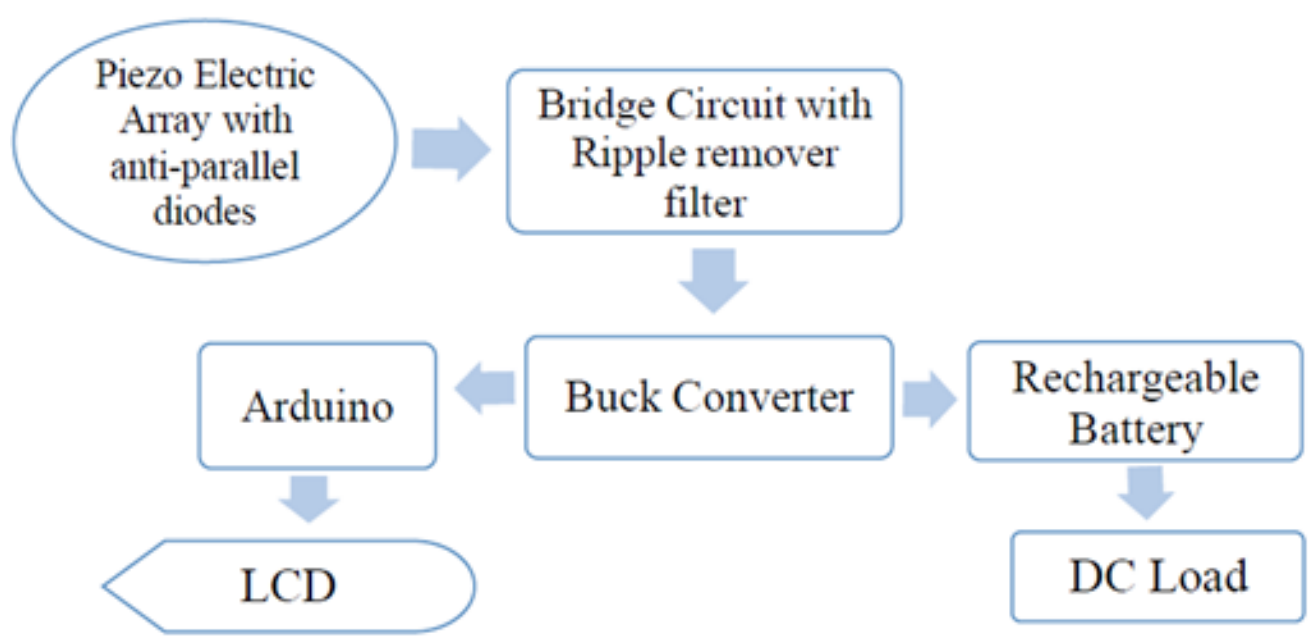

Fig 2. Working diagram of piezoelectric

Piezoelectric transducers convert stress or pressure into electrical power. The stress or pressure can be applied by using human locomotive (i.e., footsteps). As we are familiar with the power generation of a single piezoelectric disc that it could not generate much power, to overcome this problem, a tile containing several piezoelectric transducers arranged in a series-parallel configuration is used to get enough power. The output produced is in the variable form, whereas we are required to produce linear voltage, so for that, we use a bridge circuit to get pure DC Voltage. Then an AC filter circuit is used in order to eliminate the further fluctuations in the circuit output voltage. We use a buck converter (LM 2596) between the rectifier circuit and the battery. Buck converter step-downs the voltage to a level required to charge the battery and the aurdino, LCD both operates on $5 \mathrm{~V} \mathrm{dc}$ so the buck converter serves this purpose too. The output from the rechargeable DC battery is connected to power up 
the DC Load. We use an LCD to display our produced voltage resulted from the applied pressure on the piezo transducer, LCD is connected to Arduino, and an AC/DC current sensor (ACS712) is used to measure the produced voltage results. Figure 2 shows the working flow of the design, and Figure 3 shows hardware connections of the project.

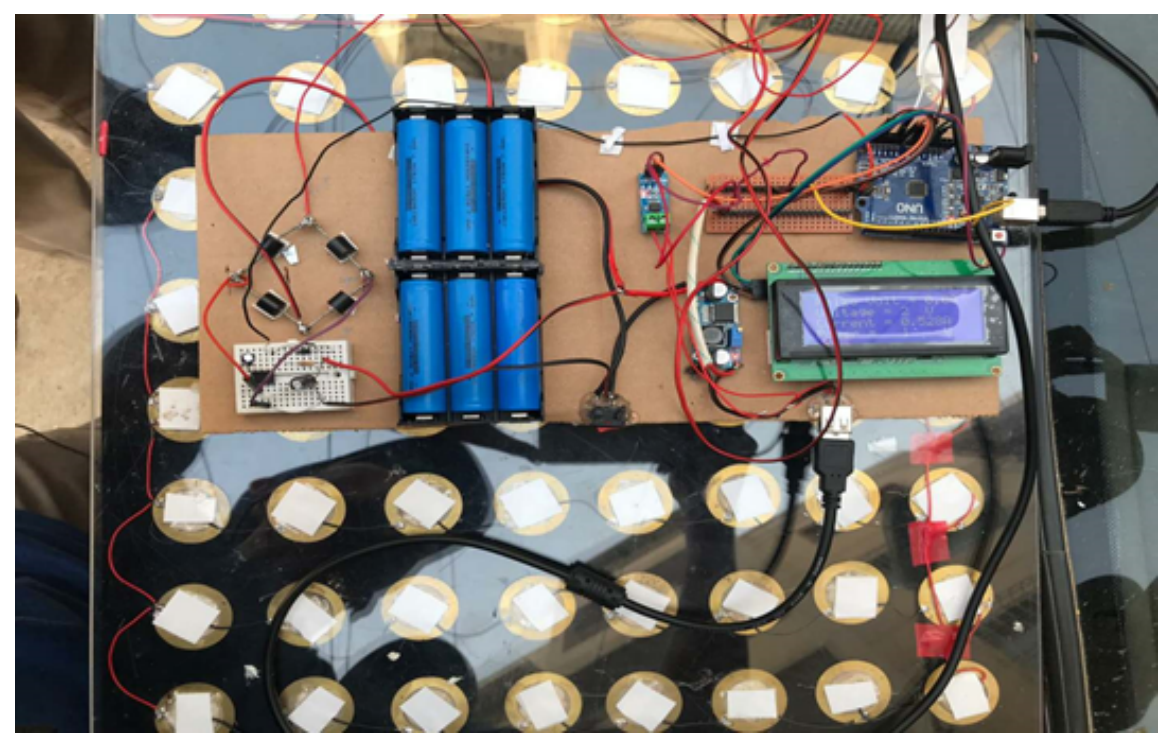

Fig 3. Hardware shows connectivity of piezoelectric discs and other equipments

\section{Results and Discussion}

In this work, our purpose is to connect many piezo transducers in a series-parallel manner to observe the amount of power generated. During working on designing this project, we connected our entire configured piezo transducers in series-parallel manners and connecting with rectifiers, the flow observed was similar as represented in the working and schematic diagram. We observe $45 \mathrm{~V}$ without using anti-diodes, but the problem of inverse piezo effect occurred in transducers; therefore, reverse current flowing in the transducers and piezo particles generated which damage the transducers. That results in damaging many piezo transducers. In order to sort out the trouble-causing inverse piezo effect, we added a diode in anti-parallel across each bridge rectifier. Due to which the reverse current flowing into piezo transducers diodes are causing to block the reverse flow of rushing current. Figure 4 shows multiple piezo transducers in a series-parallel manner that generating with a peak of almost 20 volts.

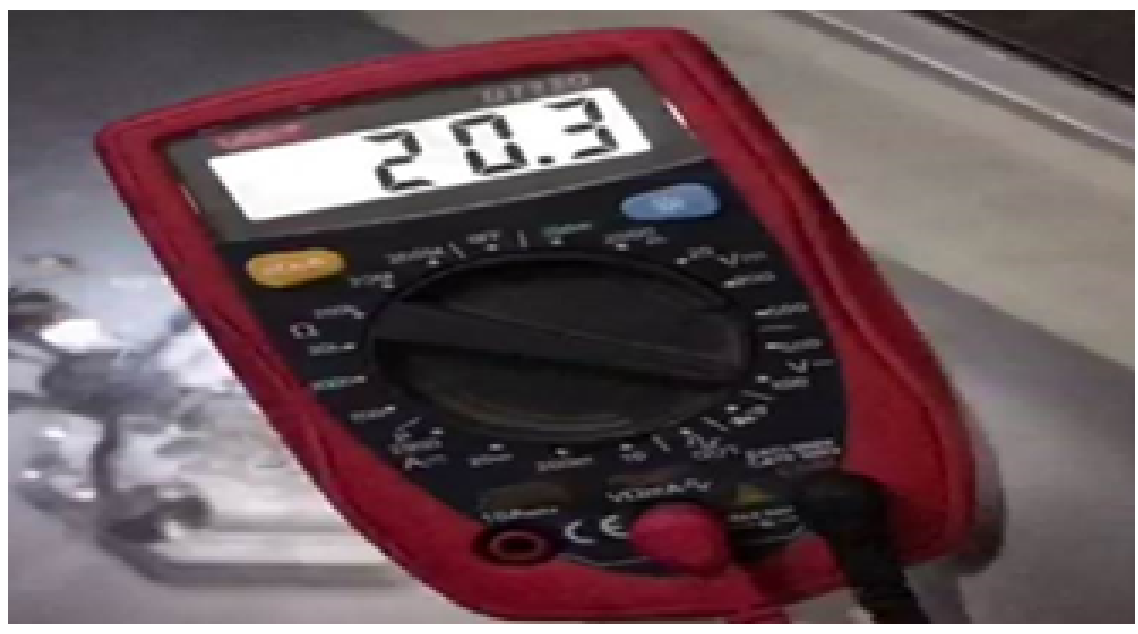

Fig 4. Result shows output voltage at applied weight using multiple piezoelectric disces connected with anti-parallel diodes 
We also observed and analyzed the results by using the different number of piezo transducers in series and parallel order of measure the power generated. Figure 5 shows that a single piezo transducer generates approximately $4 \mathrm{~V}$ of output. Whereas, in Figure 6 , results show two transducers produce $14 \mathrm{~V}$ of output. In this analysis, we configured piezo transducer in series and got their peak pulses of voltages based on applied pressure.

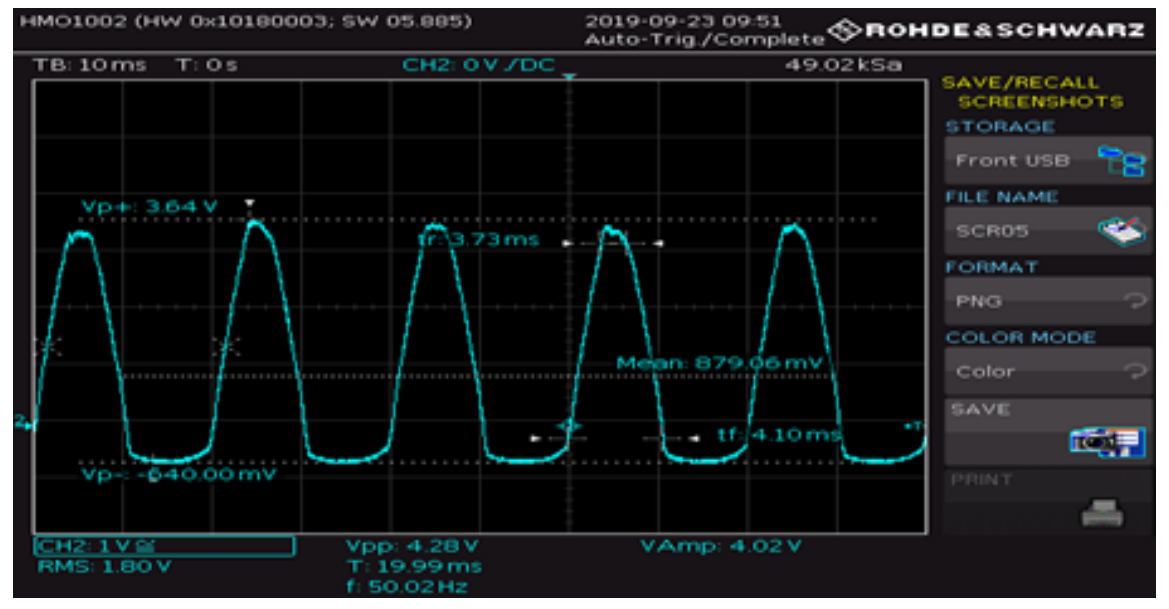

Fig 5. Results shows output voltage at applied weight using 1 piezoelectric disc

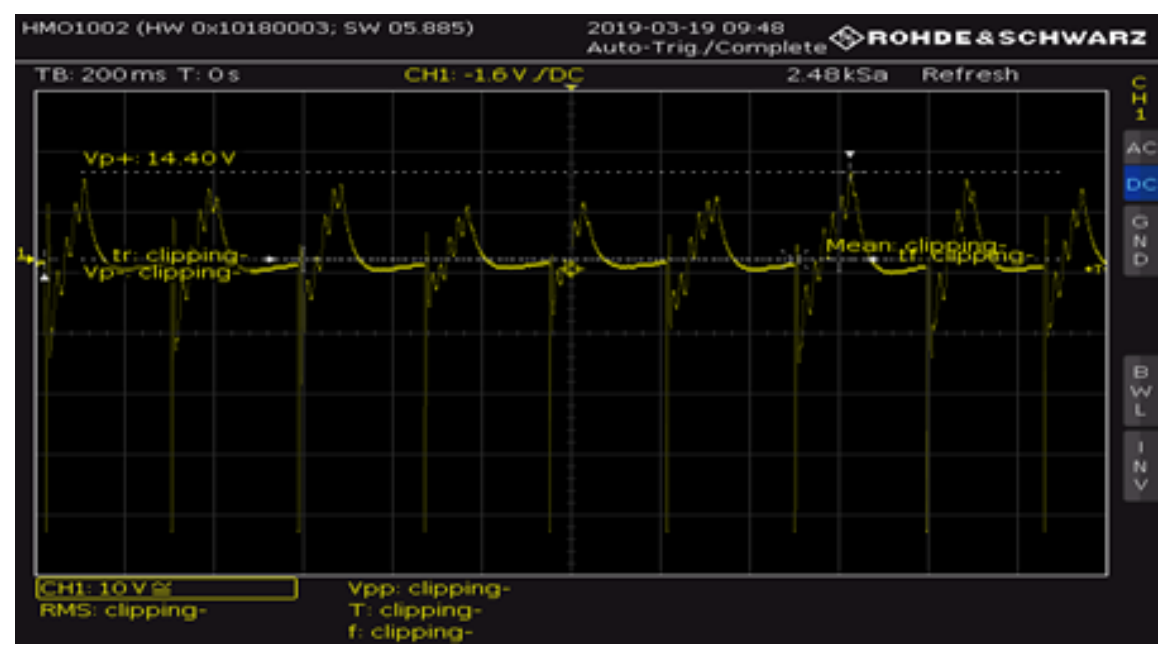

Fig 6. Results shows output voltage at applied weight using 2 piezoelectric disc in series

The sustainable pedestrian power generator is designed using piezo electric sensors, above results shows the relation of power generated using different number of piezoelectric discs in series and parallel order. The generated electric charges by applied pressure can be considered as ideal capacitor, therefore the equivalent voltage generated by more than one piezoelectric discs connected in series is sum of all piezo electric discs. The high power can be produced using limited number of piezoelectric sensors but due to inverse piezoelectric effects it damages the piezoelectric disks. To increase the life of piezoelectric materials we used anti-diodes. This is renewable energy unlike the ones from fossil fuels, here we convert one form of energy to another form. By using piezoelectric sensors, the generating power is cheap, sustainable and relative zero running costs considered.

\section{Conclusion}

We configured the hardware for generating electrical energy using piezoelectric materials. In this project, the pressure or stress applied to piezoelectric installed tiles where the mechanical energy (by the vibration of tiles) is converted to electrical energy. Inorder to overcome the inverse piezo effects, which damages the piezo material, we used anti-diodes, which increases the piezo 
material life. Moreover, we successfully generated 45V without using anti-diodes, but it damages many piezo materials. We also observed power generated by single piezoelectric and 2 piezoelectric materials in series, which produce $4 \mathrm{~V}$ and $14 \mathrm{~V}$ respectively by applying different weights. Finally, we configured multiple piezo transducers in series-parallel order with anti-diodes, which give $20 \mathrm{~V}$ of output power at the applied weight. The high life time of sensors, large voltage generation and no use of anti-diodes; makes this design comparatively better than its counterparts.

\section{Acknowledgement}

We are thankful to anonymous reviewers.

\section{References}

1) Charriau P, Lapillonne B, Crenes M. Global Energy Trends 2020 Edition. 2020. Available from: https://www.enerdata.net/publications/reportspresentations/world-energy-trends.html.

2) Zohuri B, Mcdaniel P. The Electricity: An Essential Necessity in Our Life BT - Advanced Smaller Modular Reactors. In: B Z, P M, editors. An Innovative Approach to Nuclear Power. Springer International Publishing. 2019;p. 1-21.

3) Baniya P, Barge S, Patil R, Yewale PP. Power Generation using Piezoelectric Material. 2019. Available from: https://www.irjet.net/archives/V6/i5/IRJETV6I5919.pdf.

4) Chouhan P, Netula OP. Footstep Power Generation Using Piezo-Electricity. International Journal of Engineering Sciences \& Research Technology. 2017;6(4):515-523. Available from: http://www.ijesrt.com/issuespdffile/Archive-2017/April-2017/79.pdf.

5) Xu X, Cao D, Yang H, He M. Application of piezoelectric transducer in energy harvesting in pavement. International Journal of Pavement Research and Technology [Internet]. 2018;11(4):388-395. Available from: https://doi.org/10.1016/j.ijprt.2017.09.011.

6) Tian X, Liu Y, Deng J, Wang L, Chen W. A review on piezoelectric ultrasonic motors for the past decade: Classification, operating principle, performance, and future work perspectives. Sensors and Actuators, A: Physical. 2020;306. Available from: https://doi.org/10.1016/j.sna.2020.111971.

7) Boby K, Paul KA, Anumol CV, Thomas JA, Nimisha KK. Footstep Power Generation Using Piezo Electric Transducers. International Journal of Engineering and Innovative Technology. 2014;3(10):264-267. Available from: http://www.ijeit.com/Vol3/Issue10/IJEIT1412201404_51.pdf.

8) MaghsoudiNia E, WanAbdullahZawawi NA, MahinderSingh BS. Design of a pavement using piezoelectric materials. Materialwissenschaft und Werkstoffechnik. 2019;50(3):320-328. Available from: https://dx.doi.org/10.1002/mawe.201900002.

9) Covaci C, Gontean A. Piezoelectric Energy Harvesting Solutions: A Review. Sensors. 2020;20:3512-3512. Available from: https://dx.doi.org/10.3390/ s20123512.

10) Marshiana D, Sherine ME, Sunitha N, Vinothkumar C. Footstep Power production using Piezoelectric Sensors. Research Journal of Pharmacy and Technology. 2016;9(7):831-831. Available from: https://dx.doi.org/10.5958/0974-360x.2016.00157.8. 